\title{
Cataloging Efficiency and Effectiveness
}

\section{Cheryl McCain and Jay Shorten}

Efficiency and effectiveness of technical services units are difficult to measure, analyze, and compare, partly because operations are complex and vary substantially from one library to another. Cost studies have been widely conducted as a means of measuring the cost efficiency of specific technical services tasks. Since data on costs are not necessarily comparable among institutions, other quantifiable measures of efficiency and effectiveness would enhance managerial decisionmaking. This article reports the analysis of data compiled from a survey of twenty-six academic libraries. It seeks to supplement the findings of cost studies by providing measures of efficiency and effectiveness for cataloging departments based on reported productivity, number of staff, task distribution, and quality measures such as backlogs, authority control, and database maintenance. Benchmark productivity levels for six libraries with "best practices" are identified.

$\mathbf{W}$ fficiency and effectiveness of technical services procedures are difficult to 1 analyze, partly because operations vary substantially from one library to another. Serials check-in may be performed in acquisitions at one library, by a separate serials department at another library, or delegated to staff at branch libraries. The selection and import of bibliographic records may be performed entirely by cataloging staff at one library, while acquisitions staff may perform a large percentage of this task at another library. Responsibility for the performance of other technical services functions (such as marking, security tagging, and bindery) also varies among libraries' cataloging, serials, and acquisitions departments.

One strategy for quantifying operations has been to complete cost studies, which identify specific tasks and compute the cost of those tasks. These studies can be illustrative of technical services efficiency: the greatest amount of output that can be achieved with the least amount of full-time equivalent (FTE) staff input. However, they fail to capture any information about effectiveness, which is quality processing completed in a timely manner.

Cost studies are not intended to reveal whether or not the current workflow is keeping up with incoming materials. A technical services manager can calculate the cost of processing a monograph without factoring in the existence or growth of a backlog. The cost of performing database maintenance tasks can also be calculated without considering whether or not these activities are thorough enough to insure that withdrawals, serial holdings, and other catalog corrections are up-to-date.

One major drawback to cost studies is the time and resources required to

Cheryl McCain (clmccain@ou.edu) is Acquisitions Librarian and Jay Shorten (jshorten@ou.edu) is Electronic Resources Cataloger, University of Oklahoma Libraries, Norman.

Manuscript received June 6, 2001; accepted September 27, 2001. conduct them. While it may be helpful to know another library's average costs of performing various tasks, a comparison of costs across libraries should be based on studies that utilize the same methodology. Few technical services managers conduct their own cost studies, but some make outsourcing decisions by assuming that their costs are comparable to those published in the most recent cost study. 
A survey instrument was designed to obtain benchmarking data that may help technical services managers analyze the efficiency and effectiveness of their own operations in comparison to other libraries' operations. Information about distribution of work among departments, total staffing, backlogs, perceptions of efficiency, and total volumes processed was solicited and analyzed through a survey of academic libraries that are members of the Association of Research Libraries (ARL). This article reports the survey results that focus specifically on cataloging activities during fiscal year (FY) 1998-99.

\section{Literature Review}

In the past two decades, much attention has focused on the costs of technical services operations in academic libraries. According to Kantor (1986), more than one hundred academic libraries were involved in cost studies between 1981 and 1984. Analyzing the 1982-83 ARL statistics, he found that those libraries having the lowest processing costs ranked highest in the number of volumes added per year. The inverse was also found: libraries with the highest processing costs added the fewest volumes.

This significant correlation between low cost and high productivity gives credence to the value of conducting cost studies as one measure of the efficiency of a library's technical services operations. In her discussion of technical processing costs, Bedford (1989) maintains that managers should continually obtain and analyze cost information in order to redesign workflows effectively and to reallocate resources and personnel.

Resources and examples are available to help librarians conduct cost analyses at their institutions. In 1991, the Association for Library Collections and Technical Services (ALCTS) Technical Services Costs Committee prepared a guide that outlines the steps to follow when calculating the unit costs of acquisitions and cataloging functions. Articles reporting the results of cost studies offer various methods for obtaining, analyzing, and interpreting cost data. Morris (1992) has detailed a longitudinal study at Iowa State University (ISU) that investigated the impact of automation on cataloging costs. Osmus and Morris (1992) applied this method to the serials and monographs cataloging sections at ISU and found that it cost less to catalog a monograph than a serial.

Rebarcak, Zager, and Morris (1996) described the longitudinal study again, including the methodology for investigating staffing costs for monographs acquisitions. Morris, Rebarcak, and Rowley (1996) then looked at the impact of automation on acquisitions staffing costs. They found that the cost of acquiring a monograph remained high relative to the cost of cataloging it, because, unlike automation of cata- loging tasks, automation of monograph acquisitions had really only mechanized processes that were previously performed manually.

Results of the ongoing longitudinal time and cost study at ISU continue to be reported in the professional literature. In a recent article Morris et al. (2000) report that the average cost of cataloging a title at ISU fell from $\$ 20.83$ to $\$ 16.25$ per title between $1990-91$ and 1997-98. The authors credit much of this savings to the increasing availability and quality of shared catalog and authority records via national utilities. The results of the study continue to prompt adjustments in cataloging workflow and staffing in order to maximize efficiency and effectiveness.

Time and cost studies conducted in 1982-83 and 1997-98 at the University of Oregon revealed a shift in the percentage of time spent on certain acquisitions functions. In reporting the findings, Slight-Gibney (1999) states that she would like to see other libraries conduct studies that could be compared and developed into benchmarks or "best practices" (56). Longitudinal comparison of one library's costs and workflow would become more valuable if supplemented by comparable or complementary data from other libraries.

The wealth of research conducted to determine the costs of acquiring and cataloging materials has applied to specific tasks, staffing costs, and the impact of automation. But it is difficult to find data on how many staff it takes to handle a defined workload, and how productivity and staffing compare among institutions. Informal questioning of technical services managers can reveal a dramatic difference in the number of personnel at libraries that appear to process a similar number of items through acquisitions and cataloging.

In their comparative cost study of three medium-sized research libraries, Getz and Phelps (1984) found that variations in technical services organization and workflow among their small sample were dramatic. They suggested that future research be applied "to a larger group of libraries so that characteristics of costs can be compared with other characteristics of the libraries" (219). The objective of this article is to provide a step in that direction.

\section{Method}

Attempts to gather data from individual institutions' Web sites proved futile, as most libraries posted few or no productivity statistics. Some general data were obtained from published ARL statistics, but more detailed information was needed. Therefore, a survey was designed to identify staffing levels, the amount of work performed by departments, and distribution of tasks within three common subdivisions: acquisitions, cataloging, and serials. 
Survey questions focused on staffing levels, the number of items processed, the presence and size of a backlog, the automation system in use, and perceptions of efficiency. A grid that listed several tasks was designed to help identify whether cataloging, acquisitions, serials, or other units were performing various tasks typically associated with technical services units. Respondents were asked to identify which unit(s) performed each task by indicating the percentage of each task performed in each of the various technical services units. They were also asked to list any additional duties performed by these units that would have an impact on interpretation of the data.

Three technical services supervisors at different ARL institutions reviewed a preliminary draft of the survey. Revisions were made based on their feedback, and a final review by local acquisitions and cataloging department heads helped insure clarity and reliability. Surveys were mailed to technical services managers (administrative titles varied) at each of the $111 \mathrm{ARL}$ academic libraries in the United States and Canada (Association of Research Libraries 2000).

Twenty-seven completed surveys were returned and reviewed, for a response rate of $24 \%$. Telephone and email correspondence with respondents helped clarify responses that were unclear or questionable. One survey lacked the above-mentioned grid information but provided all other data, which was included in the survey results. In all other cases information was clarified and all 27 surveys were deemed acceptable. Of the 27 respondents, 25 libraries were located in the United States and two in Canada.

\section{Findings}

The number of total volumes held in FY 1998-99 by responding libraries ranged from 1.8 million to 5.3 million, with an average of $2,838,845$ and a median of $2,449,366$. Total library materials expenditures for responding libraries ranged from $\$ 2.5$ million to $\$ 12.8$ million, with an average of $\$ 6,109,636$ and a median of $\$ 5,264,739$. Comparing the respondent pool to all ARL academic libraries reveals that survey respondents are more representative of smaller and medium-size ARL libraries (see figures 1 and 2). The number of total volumes held by all ARL academic libraries ranged from $1,762,898$ to $14,190,704$, with an average of $3,589,357$ and a median of 2,772,663 million (Kyrillidou and O'Connor 2000). The total library materials expenditures for all ARL academic libraries ranged from $\$ 2,501,940$ to $\$ 21,225,368$, with an average of $\$ 7,027,039$ and a median of $\$ 5,991,177$.

The survey asked respondents to name the library automation software in use during FY 1998-99. No signifi- cant correlations (using Pearson's $r$ ) between productivity measures and software were found. However, six respondents indicated that their libraries had either been or were now in transition to new catalog software. The implementation of new software would certainly have an initial impact on cataloging productivity, but survey questions and data did not provide information that would lead to any clear conclusions.

Survey respondents were asked to estimate the FTE of all technical services staff that also performs some public services duties. The survey did not ask that specific public services duties be identified or that separate numbers be reported for cataloging and acquisitions staff. Thirteen of 27 technical services units reported that none of their staff perform additional duties in a public services area. Of those that indicated some staff do have duties outside of the unit, 8 libraries reported an FTE of 0.5 or less, 4 reported this FTE to be between 0.5 and 3 , and 2 reported an FTE greater than 3. Two of the responding libraries provided written comments indicating that their answers pertained only to acquisitions and serials staff. These responses indicate that staff having to perform additional duties in a public services area does not significantly affect the cataloging units represented in this study.

\section{Task Distribution}

Table 1 summarizes survey responses about where selected duties are performed in various technical services units. For example, 24 libraries indicated that some percentage of authority record updating was performed in their cataloging department. The mean of all of the reported percentages was calculated for an average of $77 \%$. An average of $20 \%$ of the total of all 24 libraries' authority work was outsourced (only 8 of the 24 libraries reported outsourcing some of their authority work).

In another example, table 1 shows the average percentage of bibliographic record import performed in each of the various library departments. For all reporting libraries, an average of $47 \%$ of record import was performed in cataloging, $39 \%$ in acquisitions, $2 \%$ in serials, $7 \%$ in other units, and $6 \%$ through outsourcing.

Information on the distribution of technical services tasks provides insights that might help explain variations in libraries' cataloging efficiency and effectiveness. In general, the task distribution (table 1) reveals that cataloging departments have the majority of the responsibility for the first six tasks listed. The responsibility for importing bibliographic records, marking and labeling, and security tagging is shared across departments. It is also interesting to note that fewer than half $(n=13)$ of the respondents reported performing union list maintenance. 


\section{Number of Volumes and Titles Cataloged}

Twenty-five libraries reported the total number of volumes cataloged during FY 1998-99, ranging from 24,585 to 171,912 . The average number of volumes cataloged was 53,364, the median was 45,996, and the standard deviation was 30,233.

The total number of titles cataloged (24 libraries reporting) ranged from 10,140 to 120,511 . The average number of titles cataloged was 40,376, the median was 31,036, and the standard deviation was 26,226 .

\section{Outsourcing}

Of the 26 respondents who provided information about the distribution of tasks among technical services units, $16(61.5 \%)$ reported outsourcing a portion of at least one task. The tasks reported most often as being outsourced by cataloging departments were: authority control, selection and import of bibliographic records, marking/ labeling, security tagging, and original cataloging. As can be seen on table 1 , the overall percentage of tasks handled through outsourcing is quite low, with authority work being the exception. If libraries outsource authority work, the savings of time and personnel should allow them to achieve increased efficiency in other tasks. The more cataloging they do with the same number of in-house personnel, the more efficient they will be.

\section{Database Maintenance}

Table 2 depicts the productivity of two staff-intensive tasks usually associated with cataloging units. The numbers of authority record updates and holdings updates per FTE staff are shown, revealing that some libraries place more emphasis than others on these tasks. The FTE for student employees was included in the calculations because students often perform some aspect of these tasks. Calculations excluded the responses from two libraries that provided one combined total for both tasks.

Fourteen respondents reported the number of updates made to their authority records, and 13 respondents left the question blank. However, 5 of the 13 indicated elsewhere on the survey that they outsource a large percentage of their authority work, which might explain why they did not have a number to report. The average number of authority 
updates per FTE was 1,999; the median was 966 and the standard deviation was 2,831 .

Thirteen institutions reported the number of holdings updates made to their catalogs per FTE during FY 1998-99, with an average of 4,057, a median of 635 , and a standard deviation of 8,132 . As with authority updates, several respondents indicated that their institutions do not collect this data, while others left these questions blank. No libraries reported outsourcing this task.

\section{Original Cataloging}

Twenty-four respondents returned data on the volume of original cataloging performed, with a minimum of 353 and a maximum of 10,099 volumes cataloged. The average number of titles requiring original cataloging was 2,826; the median was 2,288 and the standard deviation was 2,383. Table 3 shows the amount of original cataloging performed per FTE, by library. Calculations of the FTE for original cataloging included both professional and paraprofessional staff. The FTE for students was excluded, as they were considered unlikely to perform any aspects of this task.

Table 3 also includes a column showing the percentage of original cataloging that each library outsourced. The library with the highest number of original titles per FTE outsourced $3 \%$ of its original cataloging, while the library that outsourced $75 \%$ of its original cataloging ranked twelfth in comparison to the other libraries.

One would assume that libraries that outsource some of their original cataloging would show the most efficiency, since "hidden" personnel resources would be available to perform some of that task. However, the findings did not show this. Perhaps outsourcing libraries increase their effectiveness by eliminating or reducing backlogs. Another explanation may be that outsourcing of original cataloging frees personnel to address other quality tasks, such as authority control or database maintenance.

\section{Backlogs}

Twenty-two of 27 libraries $(81.5 \%)$ reported having a backlog (items held more than 30 days before being processed) of materials in their technical services departments. Survey questions did not differentiate between
Table 2. Database Maintenance Efficiency

\begin{tabular}{|c|c|c|c|c|}
\hline Library & $\begin{array}{l}\text { No. of } \\
\text { authority } \\
\text { record } \\
\text { updates per } \\
\text { FTE* }^{*}\end{array}$ & $\begin{array}{c}\text { Rank } \\
\text { (authority } \\
\text { record } \\
\text { updates) }\end{array}$ & $\begin{array}{c}\text { No. of } \\
\text { holdings } \\
\text { updates per } \\
\text { FTE* }\end{array}$ & $\begin{array}{c}\text { Rank } \\
\text { (holdings } \\
\text { updates) }\end{array}$ \\
\hline $\mathrm{N}$ & 9,268 & 1 & + & \\
\hline G & 7,228 & 2 & 16,349 & 2 \\
\hline $\mathrm{P}$ & 2,826 & 3 & 2,229 & 4 \\
\hline $\mathrm{Y}$ & 2,501 & 4 & 545 & 8 \\
\hline $\mathrm{T}$ & 1,831 & 5 & + & \\
\hline J & 1,531 & 6 & $t$ & \\
\hline A & 966 & 7 & + & \\
\hline $\mathrm{L}$ & 912 & 8 & + & \\
\hline $\mathrm{U}$ & 494 & 9 & 130 & 12 \\
\hline $\mathrm{C}$ & 180 & 10 & 3,188 & 3 \\
\hline AA & 113 & 11 & 706 & 6 \\
\hline $\mathrm{X}$ & 111 & 12 & $26,871 * *$ & 1 \\
\hline I & 25 & 13 & 138 & 11 \\
\hline $\mathrm{E}$ & $\S$ & & $\S$ & \\
\hline $\mathrm{S}$ & $\$$ & & $\$$ & \\
\hline K & 0 & 14 & $\stackrel{t}{+}$ & \\
\hline M & $t$ & & 182 & 10 \\
\hline $\mathrm{O}$ & + & & 27 & 13 \\
\hline $\mathrm{R}$ & + & & 635 & 7 \\
\hline $\mathrm{V}$ & + & & 1,244 & 5 \\
\hline W & 克 & & 499 & 9 \\
\hline
\end{tabular}

Notes: *FTE includes student employees for both tasks.

**High due to completion of a special project.

Libraries not listed did not provide responses for either task.

$\S=$ provided a combined total for holdings and authority updates;responses were treated as incomplete and not used for these calculations.

$\neq$ not reported. 
backlogs in acquisitions and cataloging units. However, comments written on the survey indicate that the numbers refer primarily to cataloging backlogs. Table 4 summarizes responses to the open-ended question of how the backlog could be eliminated given the necessary resources. For most libraries, that resource appears to be more staff to do the work. Ten indicated they would hire more staff, seven stated they would utilize outside staff (outsource), and two needed to fill vacant positions.

The survey asked for the number of items in the back$\log$ and an estimate of how many months it would take to eliminate the backlog with existing staff if no other materials were received during that time. The sizes of backlogs reported ranged from 500 to 59,000 items; the average was 9,474 items, the mean was 5,000 items, and the standard deviation was 12,707 .

Estimates for the length of time it would take to eliminate the backlogs ranged from 1 to 45 months. A comparison of each library's estimate to its number of titles cataloged per month per FTE revealed that over half of the estimates were two or more times greater than the cataloging rate for regular materials. This may be due to the difficult nature of some materials in the backlogs, such as foreign language materials, titles requiring original cataloging, etc.

If it is assumed that libraries that outsource some of their tasks apply their remaining personnel to reducing backlogs, then one would expect to find that those libraries have smaller or no backlogs. Library I outsources $95 \%$ of its authority work, which is the highest percentage of outsourcing for any task. Notably, library I has no backlog.

\section{Discussion Efficiency}

Despite the prevalence and size of backlogs, most survey respondents seem to feel that their technical services units are productive and efficient. Eleven chose the statement "We are efficient and have enough staff to do all our processing in a timely and efficient manner," and ten chose the statement "We are efficient, but need more staff to get materials processed in a timely manner." Five respondents selected the statement "We could be more productive, but we compare favorably to our peers." One library did not respond to this question, and no libraries selected the statement "We need to make changes to equal the productivity and effectiveness of our peers."

Analysis (Pearson's $r$ ) of these responses in comparison to actual cataloging efficiency (table 5) revealed no significant correlation between perceptions of efficiency and actual productivity based on the number of volumes cataloged per FTE. Some of the most efficient libraries did not see themselves as efficient and timely, but rather as efficient but

\begin{tabular}{|c|c|c|c|c|c|}
\hline Rank & Library & $\begin{array}{l}\text { No. of } \\
\text { titles per } \\
\text { FTE* }\end{array}$ & $\begin{array}{c}\% \\
\text { Outsourced }\end{array}$ & $\begin{array}{c}\text { FTE } \\
\text { Para- } \\
\text { professionals }\end{array}$ & $\begin{array}{l}\text { FTE } \\
\text { Catalogers } \\
\text { s }\end{array}$ \\
\hline 1 & A & 242 & 3 & 38.0 & 3.8 \\
\hline 2 & W & 234 & & 6.0 & 2.0 \\
\hline 3 & $\mathrm{AA}$ & 233 & & 9.0 & 3.0 \\
\hline 4 & S & 231 & & 22.0 & 11.5 \\
\hline 5 & G & 231 & & 16.0 & 6.0 \\
\hline 6 & $\mathrm{Z}$ & 208 & & 9.0 & 3.0 \\
\hline 7 & $X$ & 194 & & 10.5 & 4.0 \\
\hline 8 & $\mathrm{R}$ & 174 & & 11.0 & 9.0 \\
\hline 9 & $\mathrm{~N}$ & 156 & & 12.5 & 8.0 \\
\hline 10 & $\mathrm{~F}$ & 153 & 5 & 28.0 & 6.0 \\
\hline 11 & $\mathrm{Q}$ & 123 & & 4.8 & 3.0 \\
\hline 12 & $\mathrm{~L}$ & 119 & 75 & 13.0 & 3.0 \\
\hline 13 & $\mathrm{Y}$ & 117 & & 15.1 & 8.0 \\
\hline 14 & M & 95 & & 17.0 & 5.0 \\
\hline 15 & $\mathrm{U}$ & 90 & & 40.0 & 19.0 \\
\hline 16 & $\mathrm{~K}$ & 80 & & 8.0 & 1.0 \\
\hline 17 & $\mathrm{O}$ & 80 & & 10.0 & 6.0 \\
\hline 18 & B & 62 & & 20.0 & 6.5 \\
\hline 19 & I & 59 & & 4.0 & 2.0 \\
\hline 20 & $\mathrm{~V}$ & 58 & & 16.0 & 9.0 \\
\hline 21 & $\mathrm{E}$ & 57 & & 28.0 & 16.0 \\
\hline 22 & $\mathrm{~J}$ & 55 & & 6.0 & 8.0 \\
\hline 23 & $\mathrm{~T}$ & 42 & & 15.0 & 9.0 \\
\hline \multirow[t]{4}{*}{24} & $\mathrm{P}$ & 20 & & 13.0 & 5.0 \\
\hline & $\mathrm{C}$ & 苦 & & 10.0 & 5.0 \\
\hline & $\mathrm{D}$ & + & & 6.2 & 6.0 \\
\hline & $\mathrm{H}$ & 索 & 20 & 12.0 & 6.0 \\
\hline
\end{tabular}

Notes: *FTE includes student employees for both tasks.

$\neq$ not reported.

Table 4. Backlogs

Reasons for or proposed solutions
Hire more staff
Outsource some task(s)
Need money or grants
Fill vacant positions
Due to migration
Gifts done in summer
Need more workstations
Reduce public service duties
Restructure workflow
Not concerned about it

No. of responses*

10

7

3

2

2

2

1

1

1

1

4

Notes: 22 out of 27 libraries responded.

*Some libraries gave more than one response.

understaffed. The respondent with the lowest number of volumes cataloged per FTE rated itself as efficient and timely.

Table 5 shows the efficiency of each library according to the number of volumes cataloged and the number of titles cataloged. Efficiency was calculated by dividing each library's reported number by the FTE of its cataloging staff, excluding student positions. The FTE for student employees was 
not included because they are not likely to be involved in any higher level cataloging procedures.

Based on the number of volumes cataloged, the most efficient cataloging department processed 5,056 volumes per FTE. The least number of volumes processed per FTE was 866. For the number of titles cataloged, the most efficient library cataloged 4,460 titles per FTE. The least number of titles cataloged per FTE was 786 .

The number of volumes or titles cataloged per FTE should not be considered the sole indicator of efficiency. Variations in workflow can either raise or lower the efficiency rate of technical services units. Factors such as special projects, migration to a new automated system, staff vacancies, and personnel changes would be likely to cause temporary reductions in efficiency. Other factors, such as outsourcing or shifting some tasks to other units, could result in increased efficiency of volumes and titles cataloged. The decision not to perform certain tasks, such as union list holdings maintenance, could free personnel to perform other tasks at a higher efficiency rate. Libraries may also vary in the level of descriptive cataloging they perform, resulting in more or less time spent on each record. The additional responsibilities that librarians with faculty and professional status have will affect the amount of time they spend cataloging materials. This study is not intended to account for all of these circumstances, and consideration of this data as a benchmark for efficiency should be viewed with those limitations in mind.

\section{Effectiveness}

Defining effectiveness for a technical services department is not easy. As mentioned earlier, a department may appear efficient if its ratio of items processed per FTE is high. However, the same department may have a backlog that delays the timely processing of materials. Another possibility is that a department may lower the catalog quality by not maintaining authority control. In their article on the benefits of outsourcing authority control, Tsui and Hinders (1998) reinforce the importance of authority work: "Authority control-consistency of bibliographic record headings-is the most important quality of any library catalog since it has direct impact on the effectiveness of searching and retrieval" (44). Authority control is a necessary component of cataloging effectiveness.

Another indicator of effectiveness is the timeliness and frequency of catalog updates. Regular updates insure catalog currency by accurately reflecting transfers, withdrawals, and other status changes. A multitude of other factors related to good workflow design can reduce duplication of effort, eliminate procedures no longer needed, and maximize technological capacity that enhances accuracy. A complete picture of effectiveness for any library should include

\begin{tabular}{|c|c|c|c|c|}
\hline Library & $\begin{array}{l}\text { Volumes } \\
\text { Cataloged } \\
\text { per FTE* }\end{array}$ & Rank & $\begin{array}{c}\text { Titles } \\
\text { Cataloged } \\
\text { per FT }\end{array}$ & Rank \\
\hline $\mathrm{F}$ & 5,056 & 1 & 3,544 & 3 \\
\hline I & 5,028 & 2 & 4,460 & 1 \\
\hline Q & 4,989 & 3 & 4,265 & 2 \\
\hline W & 4,140 & 4 & 2,691 & 8 \\
\hline $\mathrm{R}$ & 3,931 & 5 & $\stackrel{t}{+}$ & \\
\hline $\mathrm{H}$ & 3,334 & 6 & $\stackrel{t}{+}$ & \\
\hline $\mathrm{L}$ & 3,174 & 7 & 1,702 & 15 \\
\hline $\mathrm{J}$ & 3,008 & 8 & 2,781 & 5 \\
\hline $\mathrm{N}$ & 2,956 & 9 & 2,902 & 4 \\
\hline K & 2,732 & 10 & 1,127 & 21 \\
\hline $\mathrm{Z}$ & 2,686 & 11 & 2,149 & 11 \\
\hline $\mathrm{O}$ & 2,674 & 12 & 1,761 & 13 \\
\hline X & 2,314 & 13 & 2,155 & 10 \\
\hline G & 2,297 & 14 & 1,619 & 16 \\
\hline $\mathrm{P}$ & 2,187 & 15 & 2,448 & 9 \\
\hline M & 2,133 & 16 & 1,746 & 14 \\
\hline D & 2,118 & 17 & 1,865 & 12 \\
\hline $\mathrm{E}$ & 1,920 & 18 & 1,259 & 19 \\
\hline V & 1,881 & 19 & 1,155 & 20 \\
\hline Y & 1,604 & 20 & 1,344 & 18 \\
\hline S & 1,582 & 21 & 786 & 24 \\
\hline B & 1,532 & 22 & 1,517 & 17 \\
\hline $\mathrm{T}$ & 1,510 & 23 & 1,018 & 22 \\
\hline C & 1,383 & 24 & $\stackrel{+}{+}$ & \\
\hline $\mathrm{U}$ & 866 & 25 & 870 & 23 \\
\hline A & + & & 2,737 & 7 \\
\hline $\mathrm{AA}$ & + & & 2,773 & 6 \\
\hline
\end{tabular}

Notes: *FTE includes only professionals and paraprofessionals.

$\neq$ not reported

several measures. Three factors included as measures of effectiveness for this study were the presence, nature, and size of backlogs; the practice of authority control; and holdings maintenance.

\section{Conclusion}

Review and comparison of all the tables can provide an overall perspective for technical services managers. However, establishing a useful benchmark should take into account "best practices." Specifically, selecting an efficiency goal based on a library that does no authority control would be a poor choice. Benchmarks should be established by focusing on those libraries that are efficient and effective: those libraries that fully update their catalogs, consistently maintain authority control, and do not have unmanageable backlogs.

Table 6 depicts six libraries, all of which meet "best practices" as defined in this paper. These libraries maintain authority control and holdings records and have moderate or no current backlogs. As can be seen in table 6, library G and library I perform most of these tasks in cataloging, 
except that library G performs only $10 \%$ of its security tagging in cataloging and library I outsources $95 \%$ of its authority control. Library G's cataloging department handles 100\% of thesis and dissertation processing, while at library I this responsibility is delegated to a department other than cataloging. As another example of variations in task distribution, library $\mathrm{P}$ performs a portion of security tagging and marking in cataloging while the cataloging departments of Libraries $\mathrm{X}$ and $\mathrm{Y}$ do not perform any percentage of these tasks.

Libraries U, X, and Y reported " $\mathrm{n} / \mathrm{a}$ " for union list maintenance. Union list activities were not included as a best practice measure, since union list participation may not always be a choice for libraries but may be a function of their location and consortium agreements. However, union list participation is notable in that it can affect the workload of cataloging departments considerably.

In table 7, the same libraries are shown with their productivity per FTE staff and efficiency rankings. Library I clearly processes the most volumes and titles per FTE, but it should be remembered that library I has "hidden" resources in that it outsources a major portion of its authority work. Library G ranked second in efficiency for authority and holdings work. Its backlog is relatively small and was attributed to temporary staffing vacancies. As can been seen from tables 6 and 7 , each of these "effective" libraries varies somewhat in task distribution and volume of work.

Selection of one library as the most efficient and effective is difficult, because all cataloging departments do not perform the same percentages of the same tasks. It seems that library $\mathrm{U}$ is the least efficient, but this could be due to 1.25 FTE of its technical services staff having some public services duty. Library P has a large backlog, but it is static and related to a special collection and gifts; its currently received materials are not backlogged. Library $\mathrm{X}$ appears to be relatively efficient, with a backlog related only to gifts. However, its cataloging department lacks the responsibility that others have for marking, tagging, and union list updating.

Table 6. Percent of Tasks Performed in Catalog Department by "Best Practices" Libraries

\begin{tabular}{|c|c|c|c|c|c|c|}
\hline $\begin{array}{l}\text { Task } \\
\mathrm{Y}\end{array}$ & Library G & Library I & Library P & Library U & Library $\mathrm{X}$ & Library \\
\hline Original cataloging & 100 & 100 & 100 & 92 & 100 & 100 \\
\hline Copy cataloging & 100 & 100 & 99 & 60 & 100 & 100 \\
\hline Authority control & 100 & $5 *$ & 100 & 90 & 100 & 100 \\
\hline Holdings updates & 100 & 100 & 100 & 15 & 88 & 100 \\
\hline Union listing & 65 & 100 & 100 & + & + & $\stackrel{+}{+}$ \\
\hline Theses/dissertations & 100 & 0 & 50 & 100 & 0 & 100 \\
\hline Import bib records & 35 & 100 & 50 & 60 & 82 & 80 \\
\hline Marking/labeling & 100 & 100 & 50 & 80 & 0 & 0 \\
\hline Security tagging & 10 & 100 & 40 & 45 & 0 & 0 \\
\hline
\end{tabular}

Notes: * 95\% of authority control is outsourced

Table 7. Efficiency of Libraries with "Best Practices"

\begin{tabular}{|c|c|c|c|c|c|c|}
\hline Task & Library G & ${ }_{\text {Library I }}$ & Library P & Library U & Library X & Library \\
\hline Volumes cataloged per FTE (rank) & $\begin{array}{r}2,297 \\
(14)\end{array}$ & $\begin{array}{r}5,028 \\
(2)\end{array}$ & $\begin{array}{r}2,187 \\
(15)\end{array}$ & $\begin{array}{l}867 \\
(25)\end{array}$ & $\begin{array}{r}2,314 \\
(13)\end{array}$ & $\begin{array}{r}1,604 \\
(20)\end{array}$ \\
\hline Titles cataloged per FTE (rank) & $\begin{array}{r}1,619 \\
(16)\end{array}$ & $\begin{array}{r}4,460 \\
(1)\end{array}$ & $\begin{array}{r}2,448 \\
(9)\end{array}$ & $\begin{array}{l}870 \\
(23)\end{array}$ & $\begin{array}{r}2,155 \\
(10)\end{array}$ & $\begin{array}{r}1,344 \\
(18)\end{array}$ \\
\hline Authority updates per FTE (rank) & $\begin{array}{r}7,228 \\
(2)\end{array}$ & $\begin{array}{r}25 \\
(13)\end{array}$ & $\begin{array}{r}2,826 \\
(3)\end{array}$ & $\begin{array}{r}494 \\
(9)\end{array}$ & $\begin{array}{l}111 \\
(12)\end{array}$ & $\begin{array}{r}2,501 \\
(4)\end{array}$ \\
\hline Holdings updates per FTE (rank) & $\begin{array}{r}16,349 \\
(2)\end{array}$ & $\begin{array}{l}138 \\
(11)\end{array}$ & $\begin{array}{r}2,229 \\
(4)\end{array}$ & $\begin{array}{l}130 \\
(12)\end{array}$ & $\begin{array}{r}26,871^{*} \\
(1)\end{array}$ & $\begin{array}{r}545 \\
(8)\end{array}$ \\
\hline Original cataloging per FTE (rank) & $\begin{array}{r}231 \\
(5)\end{array}$ & $\begin{array}{r}59 \\
(19)\end{array}$ & $\begin{array}{r}20 \\
(24)\end{array}$ & $\begin{array}{r}90 \\
(15)\end{array}$ & $\begin{array}{r}194 \\
(7)\end{array}$ & $\begin{array}{l}117 \\
(13)\end{array}$ \\
\hline Total no. of volumes cataloged & 52,830 & 30,169 & 46,810 & 59,792 & 38,184 & 39,148 \\
\hline No. of items in backlog & $3,000 * *$ & 0 & $16,000 \uparrow$ & 5,000 & $5,000+$ & 847 \\
\hline
\end{tabular}

Notes: * high due to completion of a special project

** due to staff vacancies

+ longstanding backlog of special collection titles; no currently received items in backlog 
A review of all the variables is necessary before a manager can select a peer comparator as a reasonable benchmark. Considering all the variables, it seems that library $\mathrm{G}$ may be a library worthy of aspiration. However, technical services managers wishing to compare themselves with library $\mathrm{G}$ should carefully review its task distribution and size of workload. If dissimilar, a manager should pick another best practice library and consider the range of productivity between library $\mathrm{G}$ and a more similar peer.

Any benchmark should be used with some caution, as multiple variables can dramatically affect productivity factors that were not included in the survey. Still, this information can be useful to technical services managers. Finding a library with similar task distribution and comparable efficiency rate can provide an informed perspective of what may be realistic expectations for productivity. The information can also be used to supplement the findings of cost studies for a combined perspective of cost efficiency and cataloging effectiveness.

As more studies are completed, managers may be able to refine preliminary benchmarks such as these into better models that account for numerous variables. Until that time, these figures present a range of benchmarks, with qualifying variables. These results serve as a beginning analytical tool that may eventually evolve into a more accurate model for measurement.

\section{Works Cited}

Association for Library Collections and Technical Services Technical Services Costs Committee. 1991. Guide to cost analysis of acquisitions and cataloging in libraries. ALCTS Newsletter 2: 49-52.
Association of Research Libraries. 2000. ARL member libraries. Accessed March 18, 2000, www.arl.org/members.html.

Bedford, Denise A. D. 1989. Technical services costs in large academic research libraries: A preliminary report on the findings of the Samuel Lazerow Fellowship Project. Technical Services Quarterly 6(3/4): 29-48.

Getz, Malcolm, and Doug Phelps. 1984. Labor costs in the technical operations of three research libraries. Journal of Academic Librarianship 10(4): 209-19.

Kantor, Paul B. 1986. Three studies of the economics of academic libraries. Advances in Library Administration and Organization 5: 221-86.

Kyrillidou, Martha, and Michael O'Connor, eds. 2000. ARL statistics 1998-99. Washington, D.C.: Association of Research Libraries.

Morris, Dilys E. 1992. Staff time and costs for cataloging. Library Resources and Technical Services 36(1): 79-95.

Morris, Dilys E., Pamela Rebarcak, and Gordon Rowley. 1996. Monographs acquisitions: Staffing costs and the impact of automation. Library Resources and Technical Services 40(4): 301-18.

Morris, Dilys E., et al. 2000. Cataloging staff costs revisited. Library Resources and Technical Services 44(2): 70-83.

Osmus, Lori L., and Dilys E. Morris. 1992. Serials cataloging time and costs: Results of an ongoing study at Iowa State University. Serials Librarian 22(1/2): 235-48.

Rebarcak, Pam Zager, and Dilys Morris. 1996. The economics of monographs acquisitions: A time/cost study conducted at Iowa State University. Library Acquisitions: Practice and Theory 20(1): 65-76.

Slight-Gibney, Nancy. 1999. How far have we come? Benchmarking time and costs for monograph purchasing. Library Collections, Acquisitions and Technical Services 23(1): 47-59.

Tsui, Susan L., and Carole F. Hinders. 1998. Cost-effectiveness and benefits of outsourcing authority control. Cataloging and Classification Quarterly 26(4): 43-61. 